\title{
Effects to Speed and Strength Performance of Pliometric Training at Different Planes in Football Players
}

\author{
Özgür Nalbant ${ }^{1}$, Ahmet Metin Kınık ${ }^{2}$
}

${ }^{1}$ Gedik University, ozgurnalbant@hotmail.com

${ }^{2}$ Gedik University, ametinkinik@ hotmail.com

Received: 06.03.2018

Accepted: 29.03.2018

Online Published: 30.03.2018

doi: 10.30655/besad.2018.6

\begin{abstract}
This study was carried out to determine the effects of pliometric studies on the speed and strength performance of football players in sagittal and forentral plane. 60 athletes participated in the research and the average age of the team was $18.25 \pm 0.6$ year. The football players were randomly divided into three groups: sagittal group $(S G)$, frontal group $(F G)$ and control group $(K)$. Although $S G$ and $F G$ groups did pliometric training in addition to their weekly training, $K$ group didn't any training. Body composition measurements, leg strength, standing long jump, 10-meter speed, 35-meter speed, and T-test measurements were performed before and after eight weeks of study. SPSS 20 package program was used for statistical analysis. A T test was performed to assess the difference between the measures and the level of significance was assessed at $p<0.05 . T$ drill, 10 meter sprint, long jump, standing long jump were significantly different in $S G$. ( $p<0.05)$. However, there was no difference in the $35 \mathrm{~m}$ speed test. Again, there was a significant difference T drill, long jump and leg strength in FG. ( $p<0,05)$. There was no significant difference in the $10 \mathrm{~m}$ speed, the $35 \mathrm{~m}$ speed tests and the long jump test. As a result, test results showed similar results in pliometric studies in the sagittal and frontal planes.
\end{abstract}

Keywords : Soccer, Sagittal Plane, Frontal Plane, Pliometric training

\section{Futbolcularda Farklı Düzlemlerde Yapılan Pliyometrik Antrenmanların Sürat ve Kuvvet Performansına Etkileri}

\section{$\ddot{\mathbf{O} z}$}

Bu çalışma, futbolcularda sagittal ve forantal düzlemde yapılan pliyometrik çalışmaların sürat ve kuvvet performansina etkilerini belirlemek amaciyla yapild. Araştırmaya Galatasaray futbol

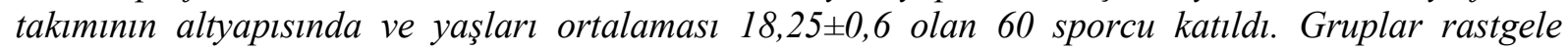
yöntemle eşit olarak sagittal grup (SG), frontal grup (FG) ve kontrol grubu (K) olarak ü̧̧ gruba ayrıldl. SG ve FG haftalık antrenmanlarına ek olarak pliyometrik çalışma yapmalarına rağmen $K$ grubu herhangi bir çalışma yapmadl. Sekiz hafta süren çalışmanın öncesinde ve sonrasında vücut kompozisyonu ölçümlerinin yanı sıra sürat ve kuvvetle ilgili; bacak kuvveti, durarak uzun atlama, 10 metre ve 35 metre sürat testleri ve T testi ölçümleri yapıldl. İstatistiksel analizde SPSS 20 paket programı kullanıldı. Ölçümler arasındaki farkın değerlendirilmesi için T Testi yapıldı ve anlamlılık düzeyi $p<0,05$ düzeyinde değerlendirildi. Yapilan değerlendirmede $S G$ ' de; $T$ drill, 10 metre sürat, durarak uzun atlama, sirt bacak kuvvetlerinde anlaml bir fark gözlendi $(p<0,05)$. Ancak $35 \mathrm{~m}$ sürat testinde ise fark yoktu. Yine $F G$ ' de T dril, durarak uzun atlama ve bacak kuvveti testlerinde anlamlı fark gözlendi $(p<0,05) .10 \mathrm{~m}$ sürat, $35 \mathrm{~m}$ sürat ve durarak uzun atlama testlerinde ise anlaml fark yoktu. Sonuç olarak sagittal ve frontal düzlemde yapılan pliyometrik çalı̧̧malarda test değerleri değişiklikler gösterse de benzer sonuçlar ortaya koymuştur. 


\section{Giriş}

Futbol, tüm milletlerin ortak tutkusu haline gelmiş sportif bir organizasyondur. Artan ilgiye paralel olarak da daha çok seyir zevki vermesi de gerekmektedir (Gencay, 1995). Futbol oyunu, milyonlarca insanı, en zor iklim şartları altında bile, statlara çeken dürüst ve üstün teknikte oynandığında kalitesi daha da artan bir spor dalı olmuştur. Gelişmiş ülkelerde ve ülkemizde bu ilgi futbolu okullara ve kulüplere taşıyarak yaşamın bir parçası haline getirmiştir (Ateş, 2006).

Yaşadığımız son yüzyıl içinde bedensel yetenekler ve performans düzeyi futbolu geliştirmek için bilimsel bilginin sınırları zorlanmaktadır. Bunun sebeplerinden biri aynı dönem içinde bireylerin, grupların, toplumların hatta ülkelerin birbirlerine olan üstünlüklerini ispat için savaş alanları yerine spor sahalarını tercih etmeleri olmuştur. Kitleler onları izlemekte, taklit etmekte ve izledikleri mücadelede kendilerini temsil eden bir simge olarak görmektedir. Ayrıca sporun milyarlarca dolarlık dev bir sektör haline gelmesi, sporcunun dolayısıyla kulüplerin ve ülkelerin başarısının önemini daha da arttırmıştır. İşte bu durumdaki sporcunun başarısının temelinde sporu en sağlıklı ve en yüksek performansta yapması yatmaktadır. Bunu sağlayacak olan ise bilimsel bilginin doğru ve uygun paylaşımla antrenmana ve sahaya taşınmasıdır (Bayraktar ve Kurtoğlu 2004)

Futbol oyunu sırasında tüketilen enerji oyuncularda bazı fizyolojik kapasitelerin bulunmasını gerektirir. $\mathrm{Bu}$ kapasiteler de oyucuların kondisyonu ve antrenman metotları ile ilgilidir. Futboldaki gereksinimler oyun sitiline, oyundaki mevkiye ve müsabaka düzeyine göre değişir. Bununla birlikte bütün oyuncular topa hakim olabilmek için veya gerek savunmada gerekse hücumda takım arkadaşlarına yardım edebilmek için her zaman aktif ve yüksek performansa sahip olmalıdırlar (Reilly, 1991).

Günümüz futbolu, daha karmaşık teknik becerilere, taktiksel düşüncedeki gelişmeye ve fiziksel ihtiyaçlardaki artışa dayanmaktadır (Akgün ve İşleğen, 1983). Büyük kitlelere hitap eden ve popülaritesini artıran futbol hız, koordinasyon, dayanıklılık, teknik ve pek çok mekanik bileşenin eş zamanlı çalışmasını gerektirmektedir (Koca, 2002).

Etkili bir antrenman, kişinin yapısına uygun olan fiziksel yüklenmelerin kullanılmasına ve spor dalının fiziksel ve fizyolojik ihtiyaçlarına dayanır. Antrenmanların etkili ve güvenli olması her şeyden önce futbolu etkileyen fizyolojik faktörlerin belirlenmesine, futbolcunun fizyolojik profilinin analiz ve değerlendirilmesine ve performansın arttırılması için uygun 
antrenman yöntemleriyle çalışmayı gerekli kılar. Futbol bir anlamda, interval spor olarak kabul edilmektedir (Günay ve Yüce, 1996). Futbolda aerobik ve anaerobik güçlerin ard arda kullanıldığı, sürat, kuvvet, çeviklik, dayanıklılık, esneklik gibi faktörlerin performansa etki ettiği bir gerçektir (Yüksek ve Cicioğlu, 2004)

Futbol, oyun esnasında yapılan ve doğrudan oyuna katkıda bulunan veya oyunun gidişine etki eden birçok hareketlerden oluşur. Futbol oyunu esnasında sarf edilen enerji oyuncularda bazı fizyolojik kapasitelerin bulunmasını gerektirir (Reilly, 1991). Antrenman ancak bu profile, fizyolojik temellere dayandığı zaman futbolcunun performansının yükseltilmesi başarılı olur (Akgün ve İşleğen, 1983). Sporcuların fiziki ve fizyolojik özelliklerinin tam olarak bilinmesi öncelikle antrenman bilimi acısından spora büyük ilerlemeler kazandırmıştır (Yüksek ve Cicioğlu, 2004).

Futbol oyunu zekâ ve ruhsal faktörlere olduğu kadar antropometrik ve fizyolojik özelliklere de büyük oranda ihtiyaç duyan bir spordur (Eker ve Ark, 2003) Fiziksel uygunluk, takımın işbirliğinin ve taktiğinin tamamlayıcı parçası iken, fiziksel uygunluğa bağlı oyunda her şey meydana gelebilir. Yüksek tempoda futbol oynayabilmek için muhakkak o seviyeye ayak uyduracak fiziksel uygunluğa sahip olmak zorunludur (Şiro, 1999).

Sportif oyunların çoğunda kullanılan antrenman yöntemlerinden biri de pliyometrik çalışmalardır. Verhoshanski, pliyometrik teknikleri derinlik sıçramaları olarak tarif ederek, egzersiz sırasında sporcu belli bir yükseklikten düşer ve düşer düşmez hemen sıçrama hareketini yapar seklinde tanımlamıştır. Pliyometrik çalışmanın kuvvet -sinir reaksiyon aktivitesini artırdığı belirtilmiştir. Ayrıca çalışmalarla dikey sıçrama becerisinin de geliştirildiği belirtilmektedir (Bedi ve Ark, 1987). Pliyometrik çalışmalar kuvvet antrenmanı ile bağlantılı bir şekilde kullanılır. Pliyometrik antrenmanlarda amaç, daha çok elastik kuvvetle ilgili olup, kasın eksantrik kasılmasından sonra konsantrik kasılma ile kısa bir zaman birimi içerisinde yüksek miktarda kuvvetin hızlı bir şekilde uygulanmasını sağlamaktır. Böylece yüksek hızda bir kasılma ile kas-sinir sisteminin direncin üstesinden gelmesi ile elastik kuvvet oluşur. Bu antrenman pozitif negatif bir kuvvet çalışması sekli olup, kinetik enerjiyi ve kuvveti oldukça hızlı bir şekilde kullanmayı amaçlar ve patlayıcı sıçrama kuvvetini geliştirir (Brown ve Ark, 1986). Pliyometrik çalışmalarda kullanılan alıştırmalarda genellikle vücut ağırlığı ve yerçekimi gibi fonksiyonlar ön plandadır. Pliyometrik çalışma içeren alıştırmalar ardışık olarak uygulanan sıçramaları, derinlik sıçramalarını, tek veya çift ayakla yapılan sıçramaları içerir. Bu alıştırmaların düzenli olarak yapılmasının bazı kasların 
neuromuscular gelişimine de yardımcı olduğu söylenmektedir (Kraemer ve Gomez, 2001). Pliyometrik egzersizlerden faydalanan antrenman programları, hız ve sıçrama gibi kuvvet-güç ilişkili hareketlerde performansa pozitif yönde etki yapmaktadır (Paul ve Ark, 2003).

$\mathrm{Bu}$ açıklamalar 1şığında yapılan çalışmanın amacı; futbolcularda farklı düzlemlerde yapılan pliyometrik antrenmanların sürat ve kuvvet performansına etkilerini değerlendirmektir.

\section{Yöntem}

Çalışmanın evrenini normal sezonu devam eden U21, U19 ve U16 takımlarında futbol oynayan sporcular oluşturdu. Örneklem grubu olarak Galatasaray Futbol Akademisi sporcuları çalışmaya gönüllü olarak katıldı. Bu araştırmada deneysel araştırma modeli olarak tekrarlı ölçümleri içeren grup içi ve gruplar arası desen kullanıldı. Çalışma için Galatasaray Futbol Akademisinde U21, U19 ve U16 takımlarında futbol oynayan 60 elit erkek futbolcu gruplarından ayrılmamak kaydıyla rastgele olarak U21 Sagittal Grup (SG), U19 Frontal Grup (FG) ve U16 da Kontrol Grubu (K) olarak belirlendi. Grupların çalışma programı rastgele seçildi. Antrenman ve müsabaka sırasında sakatlık geçiren 7 sporcu çalışmadan çıkarıldı ve çalışma 53 sporcu ile tamamland.

Sagittal grup (SG) haftada 90'ar dakikalık 5 takım antrenmanı, 90 dakikalık 1 lig maçı ve 1 gün izin yaptı. Pliyometrik çalışmalarını lig maçlarını genelde cumartesi günü oynamasından dolayı haftada iki kez salı ve çarşamba günleri 15 dakikalık ısınma sonrası, 15 dakika sagittal düzlemde pliyometrik çalışma yaptı. Pliyometrik çalışmalardan sonra normal teknik ve taktik takım antrenman düzeninde devam edildi. Frontal grup (FG) haftada 90'ar dakikalık 5 takım antrenman, 90 dakikalık 1 lig maçı 1 gün izin yaptı. Pliyometrik çalışmalarını lig maçlarını genelde pazar günleri oynamasından dolayı, haftada iki kez çarşamba ve perşembe günleri 15 dakikalık ısınma sonrası 15 dakika Frontal düzlemde pliyometrik çalışma yaptı. Pliyometrik çalışmalardan sonra normal teknik ve taktik antrenman düzenine devam edildi. Kontrol grubu (K) haftada 90'ar dakikalık dört antrenman, 80 dakikalık 1 lig maçı iki gün izin yaptı. Kontrol grup $(\mathrm{K})$ bu çalışma süresinde pliyometrik hiçbir çalışma yapmadı. SG ve FG grupları sekiz haftalık süre boyunca teknik antrenmanları dışında başka bir fiziksel çalışma yapmad1. Planlanan pliyometrik antrenman programını SG grup sagittal düzlemde ve FG grup ise frontal düzlemde yaptılar. Çalışmalar sekiz hafta boyunca devam etti. 


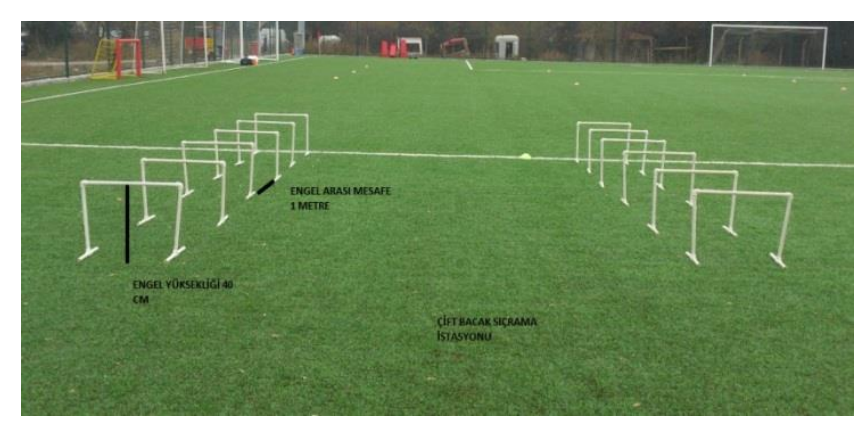

Resim 1. SG ve FG Gruplarının çift bacak pliyometrik çalışma istasyonu ölçüleri

\begin{tabular}{|c|c|c|}
\hline Engel Sayıs1 & Engel Yüksekliği & Engeller Arası Mesafe \\
\hline 6 & $40 \mathrm{~cm}$ & 1 Metre \\
\hline
\end{tabular}

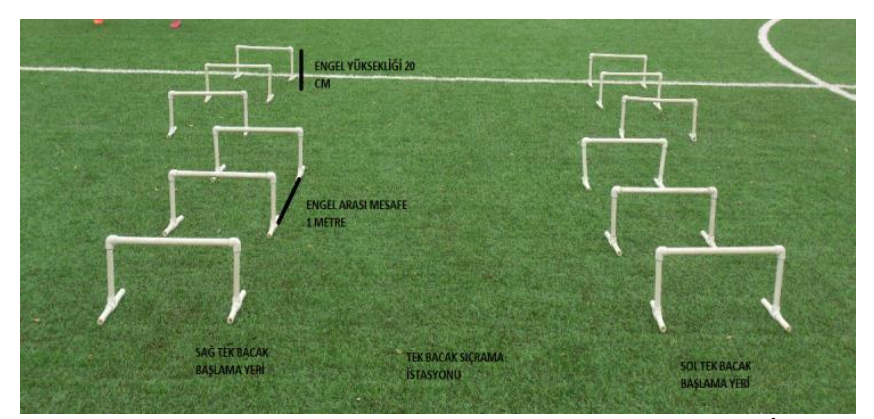

Resim 2. SG ve FG Çalışma Gruplarının Tek Bacak Sıçrama İstasyonu Ölçüleri

\begin{tabular}{|c|c|c|}
\hline Engel sayıs1 & Engel Yüksekliği & Engeller Arası Mesafe \\
\hline 6 & $20 \mathrm{~cm}$ & 1 metre \\
\hline
\end{tabular}

Tablo 1. SG ve FG grupları pliyometrik antrenman programı

\begin{tabular}{|c|c|c|c|c|c|c|c|}
\hline Set & Tekrar & $\begin{array}{c}\text { Seri Aras1 } \\
\text { Dinlenme(sn) }\end{array}$ & $\begin{array}{c}\text { Set Aras1 } \\
\text { Dinlenme(dk) }\end{array}$ & Hareket & $\begin{array}{c}\text { Cift } \\
\text { Bacak } \\
\text { Sıçrama }\end{array}$ & $\begin{array}{c}\text { Sağ tek } \\
\text { Bacak } \\
\text { S1çrama }\end{array}$ & $\begin{array}{c}\text { Sol Tek } \\
\text { Bacak } \\
\text { Siçrama }\end{array}$ \\
\hline 2 & 4 & 35 & $1-2$ & $\begin{array}{c}\text { Akıc1 } \\
\text { Tempo }\end{array}$ & 48 & 24 & 24 \\
\hline
\end{tabular}

Çalışmada SG, FG ve K gruplarının test ve ölçümleri çalışmanın başında ve sekiz haftanın sonunda alınmıştır. Katılımcıların fiziksel uygunluk ölçümleri yapıldıktan sonra 5 dakikalık ısınma ve esneklik çalışmasının ardından sırt- bacak kuvveti ölçümü yapılmıştır. Daha sonra suni çim sahada 20 dakikalık futbola özgü ısınmadan sonra T -testi, 35 metre sürat testi, durarak öne çift bacak uzun atlama, durarak sağ tek bacak uzun atlama, durarak sol tek bacak uzun atlama yapılmıştır.

Vücut Kompozisyonu Ölçümleri: Boy ölçümü sırasında katılımcının ayakları çıplak, topuklar bitişik, vücut ve baş dik olarak ölçüldü ve kaydedildi. Stadiometrenin hareketli parçası başın en üst kısmına getirildi, saçlar yeteri kadar sıkıştırılarak ölçüm 1 mm’ye kadar kaydedildi. Ölçüm sırasında katılımcılardan derin nefes almaları ve dik pozisyonlarını 
korumaları istendi (Özer, 1993). Çalışmaya katılanların ağırlıkları ve beden yağ kütlesi (\%yağ) oranı Tanita (BC418 vücut analiz monitörü) kullanılarak ölçüldü (Ateş, 2006).

Bacak Kuvvetini Ölçülmesi (BK): Sporcuların bacak kuvveti Takei Back marka bacak dinamometresi ile ölçüldü. Sporcu beş dakika ısınma yaptıktan sonra dizleri bükülü durumda dinamometre sehpasının üzerine ayaklarını yerleştirdi ve kollar gergin; sırt, düz ve gövde hafifçe öne eğikken, elleriyle kavradığı dinamometre barını dikey olarak maksimum oranda bacaklarını kullanarak yukarı çekti. Hareket iki defa tekrarlandı ve en iyi derece değerlendirmeye alındı (Ateş, 2006).

T- Testi (TT): Bu test New test 300 fotosel ölçüm cihazı

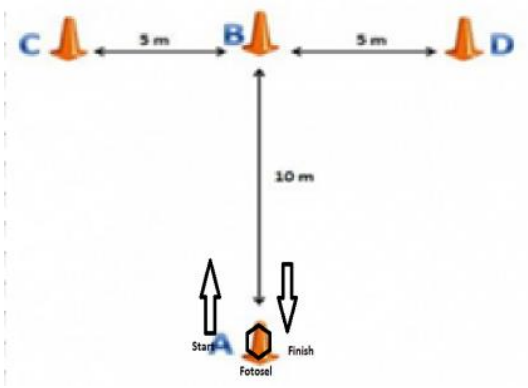

kullanılarak yapılmıştır. Şekildeki gibi sporcu "A" noktasından koşmaya başladı“B” noktasına geldi ve burada sağ eliyle koninin üstüne temas ettikten sonra sola dönerek "C" noktasına geldi ve bu kez sol eliyle koninin üstüne dokunduktan sonra dönerek "D” noktasına doğru koştu ve sağ eliyle koninin üstüne dokundu. Oradan da "B" noktasına sol elle dokunduktan sonra "A" konisine geri döndü. Her katılımcı iki kez teste katıldı ve en iyi derece çeviklik derecesi olarak kabul edildi (Kızılet ve Ark, 2010; Pauole ve Ark, 2000).

10 Metre ve 35 Metre Sürat Testi (10MS-35MS): Ölçüm New Test 300 marka fotoselle yapıldı. Düz bir hat üzerine başlangıç noktasına, 10 ve 35 metrelik mesafelere fotosel cihazları yerleştirildi. Fotosel cihazının start okuyucusu başlangıç çizgisine yerleştirildi. Katılımcının son metrelerde süratini azaltmaması için 40. metreye de bir fotosel yerleştirildi ve koşu anında katılımcıya son metrelerde süratini azaltmaması için bilgi verildi. Katılımcı hazır çık komutuyla birlikte mümkün olan en yüksek süratle mesafeyi koştu. Sporcu iki deneme yaptı ve en iyi derecesi kayıt edildi (Kamar, 2003).

Durarak Uzun Atlama Testi (DUA): Bu test için mesura kullanıldı. DUA suni çim üzerinde uygulandı. Sporcu iki kez atlayış yaptı ve en iyi derecesi kaydedildi. Katılımcı iki kez sağ tek bacak atlama (DUSAB) ve iki kez de sol tek bacak atlama (DUSOB) yaptı ve en iyi dereceler kaydedildi (Euro-Fit, 1983).

İstatiksel Analiz: Araştırmadan elde edilen verilerin çözümlenmesinde SPSS 20 istatistiksel analiz programı kullanılmıştır. Bağımlı grupların karşılaştırılmasında T testi uygulanmış ve bu testle grubun ortalamaları karşılaştırılarak, aradaki farkın rastlantısal mı, yoksa istatistiksel 
olarak anlamlı mı olduğu belirlenmişstir. Anlamlılık düzeyi $\mathrm{p}<0.05$ düzeyinde değerlendirilmiştir.

\section{Bulgular}

Yapılan çalışmaya katılan Galatasaray futbol akademisi futbolcularından elde edilen veriler ve değerlendirmelerle ilgili bilgiler aşağıda verilmiştir.

Tablo 2. SG, FG ve K Gruplarının tanımlayıcı istatistiği

\begin{tabular}{|l|c|c|c|}
\hline \multirow{2}{*}{$\mathrm{n}=53$} & SG $(\mathbf{n = 1 8})$ & $\mathbf{F G}(\mathbf{n = 1 7})$ & $\mathbf{K}(\mathbf{n = 1 8})$ \\
\cline { 2 - 4 } & A.O. \pm S.S. & A.O. \pm S.S. & A.O. \pm S.S. \\
\hline Yaş & $20,17 \pm 1,2$ & $18,59 \pm, 50$ & $16,00 \pm, 00$ \\
\hline Boy & $178,78 \pm 7,6$ & $180,24 \pm 5,964$ & $175,00 \pm 7,72$ \\
\hline A ̆̆ırlık & $72,03 \pm 7,8$ & $72,72 \pm 8,20$ & $67,66 \pm 6,95$ \\
\hline BKI & $22,52 \pm 1,1$ & $22,34 \pm 1,59$ & $22,11 \pm 1,54$ \\
\hline \%Yağ & $7,872 \pm 3,0$ & $8,26 \pm 3,48$ & $17,02 \pm 2,78$ \\
\hline
\end{tabular}

SG, FG ve K gruplarının yaş ortalamaları sırasıyla $20,17 \pm 1,2 ; 18,59 \pm, 50$ ve $16,00 \pm, 00$ 'dır. FG'nin boyu diğerlerine göre uzundur. En düşük ağırlık K grubunundur. BKI tüm gruplarda neredeyse aynıdır. \% yağ ise $\mathrm{K}$ grubunda diğerlerine göre fazladır.

Tablo 3. SG, FG ve K Grupları İlk ve Son Ölçüm Değerleri ve Karşılaştırması

\begin{tabular}{|c|c|c|c|c|c|c|}
\hline & SG & \multirow[b]{2}{*}{$\mathbf{p}$} & FG & \multirow{2}{*}{$\mathbf{p}$} & $\mathbf{K}$ & \multirow{2}{*}{$\mathbf{p}$} \\
\hline & A.O. \pm S.S. & & A.O. \pm S.S. & & A.O. \pm S.S. & \\
\hline TT 1 & $9,03 \pm 0,1$ & \multirow{2}{*}{, $000 * *$} & $9,04 \pm 0,3$ & \multirow{2}{*}{,043 } & $9,28 \pm 0,2$ & \multirow{2}{*}{, $012 *$} \\
\hline TT 2 & $8,86 \pm 0,1$ & & $8,92 \pm 0,3$ & & $9,17 \pm 0,2$ & \\
\hline 10MS 1 & $1,78 \pm 0,0$ & \multirow{2}{*}{, $001 *$} & $1,81 \pm 0,0$ & \multirow{2}{*}{, 108} & $1,84 \pm 0,0$ & \multirow{2}{*}{,018* } \\
\hline 10MS 2 & $1,77 \pm 0,0$ & & $1,77 \pm 0,0$ & & $1,80 \pm 0,0$ & \\
\hline $35 \mathrm{MS} 1$ & $4,76 \pm 0,1$ & \multirow{2}{*}{, 251} & $4,77 \pm 0,1$ & \multirow{2}{*}{,205 } & $4,93 \pm 0,2$ & \multirow{2}{*}{,106 } \\
\hline $35 \mathrm{MS} 2$ & $4,73 \pm 0,1$ & & $4,72 \pm 0,1$ & & $4,88 \pm 0,1$ & \\
\hline DUA 1 & $222,50 \pm 16,8$ & \multirow{2}{*}{, $000 * *$} & $226,88 \pm 19,6$ & \multirow{2}{*}{, $009 *$} & $221,06 \pm 10,4$ & \multirow{2}{*}{, 076} \\
\hline DUA 2 & $236,56 \pm 13,0$ & & $234,94 \pm 22,0$ & & $223,89 \pm 12,4$ & \\
\hline DUSAB 1 & $192,44 \pm 11,5$ & \multirow{2}{*}{, $001 *$} & $191,88 \pm 17,1$ & \multirow{2}{*}{, $001^{*}$} & $191,28 \pm 9,4$ & \multirow{2}{*}{,156 } \\
\hline DUSAB 2 & $197,67 \pm 7,4$ & & $199,94 \pm 14,7$ & & $194,11 \pm 12,1$ & \\
\hline DUSOB 1 & $197,83 \pm 13,2$ & \multirow{2}{*}{,602 } & $195,94 \pm 21,6$ & \multirow{2}{*}{,193 } & $190,00 \pm 10,9$ & \multirow{2}{*}{, $027^{*}$} \\
\hline DUSOB 2 & $199,06 \pm 7,0$ & & $200,53 \pm 16,7$ & & $193,44 \pm 13,4$ & \\
\hline BK 1 & $144,83 \pm 21,2$ & \multirow{2}{*}{, $000 * *$} & $146,88 \pm 17,0$ & \multirow{2}{*}{, $033^{*}$} & $125,83 \pm 32,5$ & \multirow{2}{*}{, $012 *$} \\
\hline BK 2 & $167,89 \pm 21,8$ & & $165,71 \pm 42,2$ & & $140,50 \pm 30,9$ & \\
\hline
\end{tabular}

SG'de TT, 10MS, DUA, DUSAB ve BK değerlerinde, FG' de TT, DUA, DUSAB ve BK değerlerinde ve $\mathrm{K}^{\prime}$ da ise TT, 10MS, DUSOB ve BK değerlerinde anlamlı bir fark görülmüştür $(* \mathrm{p}<0,05)$. 


\section{Tartışma ve Sonuç}

Pliyometrik antrenmanlar, antrenörler ve atletler tarafindan driller olarak bilinir. $\mathrm{Bu}$ driller hareket, hız ve kuvvet-güç üretiminde geliştirmek amacıyla kombine edilmiştir. Pliyometrik antrenmanlar daha öncelerde özellikle atıcılar ve atlayıcılar tarafından kullanılmasına rağmen günümüzde çabuk kuvvet gerektiren birçok spor dalında da kullanılmaktadır. Çoğu araştırmacı pliyometrik antrenmanların alt ekstremitelere etkilerini incelediklerinde, kas gücünü geliştiğini tespit etmişlerdir (Ateş, 2006).

Yaptığımız çalışmada SG'de TT, 10MS, DUA, DUSAB ve BK değerlerinde anlamlı bir fark görülmüştür $(* p<0,05$ ve $* * p<0,001)$. Ancak $35 \mathrm{MS}$ ve DUSOB testlerinde ise anlamlı bir fark bulunamamıştır. FG' de TT, DUA, DUSAB ve BK değerlerinde anlamlı bir fark görülmüştür $\left({ }^{*} \mathrm{p}<0.05\right)$. Ancak 10MS, 35MS ve DUSOB testlerinde ise anlamlı bir fark bulunamamıştır. $\mathrm{K}^{\prime}$ da ise TT, 10MS, DUSOB ve BK değerlerinde anlamlı bir fark görülmüştür $\left({ }^{*} \mathrm{p}<0.05\right)$. Ancak 35MS, DUA ve DUSAB testlerinde ise anlamlı bir fark bulunamamıștır (Tablo 3). Kontrol grubunda bazı değerlerde anlamlı fark çıkmasının nedeni bu grubun da aktif olarak antrenman yapıyor olmasından kaynaklandığı düşünülebilir.

Chelly (2010) futbolcularda 8 haftalık kısa süreli pliyometrik çalışmaların bacak kuvveti, sıçrama yüksekliği ve sürate etkisi olduğunu bulmuşlardır. Çalışmalarında, pliyometrik çalışma yapan grubun uyluk kasının enine kesitinde gelişme $(p<0,05)$, vücut kitle indeksi, hız, kuvvet testlerinde de anlamlı farklar $(\mathrm{p}<0,01)$, maksimal hızlarında ve 5 metrelik hızlarında anlamlı artış $(p<0,01)$ ve maksimal kuvvetlerinde de anlamlı farklar tespit etmişlerdir ( $\mathrm{p}>0,05)$. Çalışma sonucunda sezon içi pliyometrik çalışmaların bacak kuvveti, sıçrama yüksekliği ve sürati kesinlikle arttırdığını söylemişlerdir. Taheri ve Asghar (2014) 8 haftalık pliyometrik ve direnç çalışmalarının hız ve patlayıcı kuvvet üzerine etkilerine baktıkları çalışmalarında pliyometrik çalışan grubun çeviklik testlerinde $(p<0,01)$, sürat testlerinde $(\mathrm{p}<0,01)$, patlayıcı kuvvetlerinde $(\mathrm{p}<0,01)$ anlamlı farklar bulmuşladır, Direnç Antrenmanı yapan grubun çeviklik testlerinde $(p<0,01)$, sürat testlerinde $(p<0,05)$, patlayıcı kuvvet testlerinde $(\mathrm{p}<0,01)$ anlamlı farklar bulmuşlardır. Birbirleriyle karşılaştırma yaptıklarında çeviklik testlerinde Pliometrik çalışmanın Direnç antrenmanına göre anlamlı $(p<0.03)$, Sürat testlerinde Pliyometrik çalışmanın Direnç antrenmanı göre anlamlı $(\mathrm{p}<0.01)$, Patlayıcı kuvvet testlerinde Pliyometrik çalışmanın Direnç antrenmana göre anlamlı $(p<0.02)$ sonuçları olduğunu görmüşlerdir. Çalışma sonucunda pliyometrik çalışmaların direnç antrenmanlara göre daha fazla parametreyi etkilediğini söylemişlerdir. Şahin ve arkadaşlarının (2011) farklı 
yüksekliklerdeki pliyometrik çalışmalarının sürat ve dikey sıçramalarına akut etkisi isimli çalışmalarında, $30 \mathrm{~cm}$ engeller üzerinde yan sıçrama yapan grubun dikey sıçrama yüksekliğinin ileri düzeyde artı̆̆ 1 bulmuşlardır $(\mathrm{p}<0.01) .40 \mathrm{~cm}$ lik engellerden yan pliyometrik yapan grupta anlamlılık bulmamışlardır. 20 metrelik sürat testlerinde $30 \mathrm{~cm}$ lik ve $40 \mathrm{~cm}$ lik yan pliyometrik yapan gruplarda bir anlamlılık bulamamışlardır ancak 30 metrelik sürat testlerinde $30 \mathrm{~cm}$ yan pliyometrik çalışma yapan grubun 30 metrelik sürat anlamlı bulmuşlar $(p<0,05)$ fakat $40 \mathrm{~cm}$ yan bir anlamlılık bulamamışladır $(\mathrm{p}>0.05)$. Sonuç olarak 30 cm'lik yükseklikte yan pliyometrik sıçramanın dikey sıçramayı ve 30 metre sürati geliştirdiğini söylemişlerdir. Meylan ve Malatesta (2009) yaptıkları genç futbolcuların sezon içerisindeki, pliyometrik çalışmalarının patlayıcı kuvvete etkisi isimli çalışmalarında sekiz haftalık çalışmadan sonra; 10 metrelik sürat testlerinde $\% 2,1$; Çeviklik testlerinde $\% 9,2$; tekrarlı dikey sıçramalarında \%7,9; kontak reaksiyonu değerlerinde $\% 10,9$ artış bulmuşladır. Kontrol grubunda ise bir gelişme bulmamışlardır. Sonuç olarak; geleneksel futbol antrenmanlarında pliyometrik çalışmaların, patlayıcı güç, sprint ve yön değiştirme gibi parametrelere önemli ölçüde olumlu etkisi olduğu sonucunu ortaya koymuşlardır. Sedano ve arkadaşlarının (2009) yaptıkları kadın futbolcuların alt ekstremiteye yönelik pliyometrik çalışmaların vücut kompozisyonu, patlayıcı kuvvet ve şut hızına etkisi isimli çalışmada 12 haftada iki kez pliyometrik çalışma yapmışladır. Pliyometrik çalışma yapan grubun sıçrama yüksekliğinde ve patlayıcı kuvvetlerinde anlamlı bir fark bulmuşlardır $(\mathrm{p}<0,05)$. Sedano ve arkadaşları pliyometrik çalışmaların sıçrama yüksekliğine, patlayıcı kuvvette ve vücut kompozisyona olumlu etkileri olduğunu, şut gücünün ise farklılık yaratabilmesi için bir iki haftalık zamana ihtiyaç olduğunu söylemişlerdir.Thomas ve arkadaşlarının (2009) genç futbolcularda iki farklı pliyometrik çalışmanın kas gücüne ve çevikliğe etkisi isimli çalışmalarında altı hafta boyunca haftada iki kez derinlik sıçraması ve engel sıçraması yapmışladır. Çalışma sonucunda her iki grubundan dikey sıçrama yüksekliğinde ve çeviklik test zamanlarında anlamlı farklar tespit etmişlerdir $(p<0,05)$. Sürat performanslarında ise anlamlı bir fark bulamamışladır $(p>0,05)$. Sonuç olarak derinlik sıçramalarının ve tekrarlı dikey sıçramaların genç futbolcularda güç ve çevikliği geliştirmek için değerli bir antrenman olduğunu söylemişlerdir. Ronnestad ve arkadaşlarının (2008) yaptıkları elit erkek futbolcularda kısa süreli kuvvet ve pliyometrik antrenmanlarının sürat ve sıçrama performansına etkileri isimli çalışmalarında yedi haftada iki kez kuvvet antrenmanı ve pliyometrik antrenman ve bir grupta her ikisini kombine antrenman şeklinde yapmışlardır. Her iki grubun kontrol grubuna göre $1 \mathrm{rpm}$ squat, tekrarlı yarım squat, ek ağırlıklı $20 \mathrm{~kg}$, 
$35 \mathrm{~kg}, 50 \mathrm{~kg}$ ile yapılan skuat testlerinde anlamlılık bulmuşlardır $(\mathrm{p}<0,05)$. Kendi aralarında ek ağırlık ile kuvvet antrenmanı, pliyometrik yapan grupların 40 metre sprint, yarım skaut, ek ağırlıkla $20 \mathrm{~kg}, 35 \mathrm{~kg}$ ve $50 \mathrm{~kg}$ skuatta bir anlamlılık bulunmaz iken (p>0,05), kombine çalışan grupta anlamlı sonuçlar bulmuşlardır $(\mathrm{p}<0,05)$. Sonuç olarak profesyonel futbolcularda yedi haftalık güç ve kuvvet eğitimleri ölçümlerinde gelişmeler kayıt edilmiş, bu durumun sezon öncesi yapılan antrenmanlara ilgili olduğunu savunularak, bu çalışmaları daha uzun vadeli cevaplara bakmak gerektiği söylemişlerdir. Ateş ve arkadaşlarının (2007) yaptıkları pliyometrik antrenmanların 16-18 yaş grubu erkek futbolcuların bazı fiziksel ve fizyolojik parametrelere etkisi isimli çalışmada; 10 hafta süreyle haftada iki gün pliyometrik çalışma yapmışladır. Yapılan 10 haftalık antrenman programı sonucunda ön ve son testlerde ; kas gücünde, vücut yăg oranında, aneorobik güçte, esneklikte, 30 metre süratte ve 15 saniye tekrarlı sıçramada anlamlı değerler bulmuşlardır $(\mathrm{p}<0,001)$. Kontrol grubunda ise anaerobik güç ve 15 saniyelik tekrarlı sıçrama değerlerinde dışında tüm parametrelerde anlamlılık $(\mathrm{p}<0,01)$ bulmuşlardır. Sonuç olarak 16-18 yaş erkek futbolcularda antrenmanlar ile birlikte yapılan 10 haftalık pliyometrik antrenmanların, esnekliğe, anaerobik güce, maksimal ve çabuk kuvvette devamlılığın bir göstergesi olan 15 saniyelik tekrarlı sıçrama testini olumlu yönde etkilediğini tespit etmişlerdir. Dalwinder ve Sukhwinder (2013) dikey ve yatay pliyometrik egzersizlerin koşu hızına etkisi isimli çalışmalarında 10 hafta boyunca haftada iki kez dikey ve yatay pliyometrik çalışma yapmışlardır. Dikey sıçrama, Horizental sıçrama, dikey ve Horizental sıçrama kendi aralarında karşılaştırıldıklarında hız değerleri anlamsız ( $p>0.05)$ bulunur iken, kontrol grubu ile karşılaştırıldıklarında anlamlı $(p<0,05)$ bulunmuştur. Dikey siçrama -Kontrol Grubu \%2,23, Horizental -Kontrol Grubu \%2,96, Dikey- Horizental - kontrol grubu \%3,57 oranında gelişme göstermiştir. Sonuç olarak dikey, horizental, dikey horizental çalışmalardan en fazla gelişmeyi karma kombinasyonun (dikey-horizental) gösterdiğini bildirmişlerdir. Yapılan çalışmalarda ortaya konulan sürat ve kuvvet test sonuçları ile bizim çalışmamız arasında benzer sonuçlar görülmektedir.

Sonuç olarak SG'de TT, 10MS, DUA, DUSAB ve BK değerlerinde, FG' de TT, DUA, DUSAB ve BK değerlerinde ve K' da ise TT, 10MS, DUSOB ve BK değerlerinde anlamlı bir fark görülmüştür. Sagittal ve frontal düzlemde yapılan pliyometrik çalışmalarda test değerleri değişiklikler gösterse de benzer sonuçlar ortaya koymuştur. Bu tür çalışmalarda kontrol grubunun antrenman yapmayan bir grup olması çalışma için daha doğru sonuçlar ortaya koyacaktır. Aksi takdirde antrenman yapan grubun da değerleri pozitif yönde değişim gösterebilir. 


\section{Kaynaklar}

Akgün, Y. ve İşleğen, C. (1983). Futbolcuların fizyolojik profili, Spor Hekimliği Dergisi, 18 (3), ss. 105-123.

Ateş, M. (2006). Pliometrik antrenmanın 16-18 yaş grubu erkek futbolcuların üst ve alt ekstremite kuvvet parametreleri üzerine etkisi. Spormetre Beden Eğitimi ve Spor Bilimleri Dergisi, 5 (1), ss. 21-28.

Ateş, M., Demir, M., Ateşoğlu, U. (2007). Pliometrik antrenmanın 16-18 yaş grubu erkek futbolcuların bazı fiziksel ve Fizyolojik parametreleri üzerine etkisi. Nĭgde Üniversitesi Beden Ĕ̈itimi Ve Spor Bilimleri Dergisi. Cilt 1 Sayı 1.

Bayraktar, B ve Kurtoğlu, M. (2004). Sporda performans ve performans arttırma yöntemleri. Ed.: Atasu, T. Doping ve futbolda performans artırma yöntemleri, Form Reklam Hizmetleri. İstanbul. ss. 269-270.

Bed1, E.J., Creswell, A., Engle, T.S., Nicols, M. (1987). Increase in jumping height associated withmaximal effort vertical depth jumps. Research Quarterly for Exercise and Sport. 58 (1): 11-15.

Brown, M.E., Mayhew, J.L., Boleach, L.W.(1986). Effect of plyometric training on vertical jump performance in high school basketball players. Journal Sports Med Phys Fitness. 1986 March; 26 (1):1-4.

Chelly M. (2010). Effects of in season short-tern plyometric training program on leg power, jump and sprint perfomance of soccer players, Journal of Strenght and Conditioning Association. 24 (10) / 2670-2676.

Dalwinder, S., Sukhwinder, S.(2013). Effects of vertical and horizontal plyometric exercises on running speed. Human Movemnet. vol. 14 (2) 144-147

Eker, H., Ağaoğlu, Y. ve Albay, F. (2003). Niğde Üniversitesindeki 20-25 yaş arası futbol oynayan, futbolu bırakan ve düzenli spor yapmayan öğrencilerin solunum ve antropometrik Parametrelerinin incelenmesi. Spormetre Beden Ĕgitimi ve Spor Bilimleri Dergisi. I (2) 89-97.

Eurofit (1983). Euro-fit experimental battery. Prosional hand-book. Strasbourg.

Gencay, O.A. (1995). Hazırlı dönemlerinde profesyonel futbolcuları atletik performanslarının değerlendirilmesi. Yüksek Lisans Tezi. Erciyes Üniversitesi.

Günay, M. ve Yüce, A. (1996). Futbol antrenmanının bilimsel temelleri. Seren Ofset. Ankara. s: 245.

Kamar, A. (2003). Futbol oyuncularına 35 metre maksimal aerobic sprint ile dikey sıçrama ve durarak uzun atlama skorları arasındaki ilişkinin incelenmesi. $\dot{I} . \ddot{U}$. Spor Bilim Dergisi. 47-150.

Karatosun H. (1991). Futbol, çocuk ve gençlerin eğitimi. Altıntuğ Ofset 2. Baskı s: 3

Kızılet, A., Atılan, O., Erdemir, I. (2010). 12-14 yaş grubu basketbol oyuncularının çabukluk ve sıçrama yetilerine farklı kuvvet antrenmanlarının etkisi. Beden Eğitimi ve Spor Bilimleri Dergisi. 12 (2) : 44-57.

Koca, B. (2002). Farklı kategorideki sporcuların somatotip özellikleri. Antropoloji Dergisi. ss. 91-102.

Kraemer, J.W., Gomez, L.A. (2001). High-performance sports conditioning; Edit.: Foran Bill;. Human Kinetics; US 2001. 83-95.

Meylan, C., Malatesta D. (2009). Effects of in-season plyometric training within soccer practice on explosive actions of young players. Journal Strength Condition Research. Dec; 23 (9): 2605-13.

Özer, K. (1993). Antropometri sporda morfolojik planlama. İstanbul: Nobel Yayınevi. 
Paul, E.L., Jeffrey, A.P., Mathew, W.H., John, P.T., Michael, J.C. and Robert, H.L. (2003). Effects of plyometric training and recovery on vertical jump performance and anaerobic power. Journal of Strength and Conditioning Research. 17 (4).

Pauole, K., Madole, K., Garhammer, J., Lacourse, M. and Rozenek, R. (2000) Reliability and validity of the T-test as a measure of agility, leg power, and leg speed in college-aged men and women. Journal of Strength and Conditioning Research. 14 (4): 443-450.

Reilly, T. (1991). Physiological demands of soccer. Spor Hekimliği Dergisi, 26 (1), ss.41-46.

Ronnestad, B.R., Kvamme, N.H., Sunde, A., Raastad T. (2008). Short-term effects of strength and plyometric training on sprint and jump performance in professional soccer players. Journal Strength Condition Research, 22 (3): 773-80.

Sedano, C., Roel, V., Renaat, P., Gonzalo, C. (2009). Effects of lower-limb plyometric training on body composition, explosive strength, and kicking speed in female soccer players. The Journal of Strength and Conditioning Research 23 (6): 1714-22.

Şahin, M., Kırandı, Ö., Çambel, A., Kesler, A., Kamar, A., Güler, C. (2011). Farklı yükseklikteki yan pliometrik sıçramaların sürat ve dikey sıçrama parametrelerine akut etkisi. Uluslararası Hakemli Akademik Sosyal Bilimler Dergisi. 1 (1) 123-126.

Şiro, N. (1999). Diyarbakırspor ve Trabzonspor profesyonel futbol takımlarının fiziksel özellikleri ve sürat yeteneklerinin karşılaştırılması. Yayınlanmamış Yüksek Lisans Tezi. Dicle Üniversitesi.

Taheri E., Asghar N. (2014). The effect of 8 weeks of pliometric and resistance training on agility, speed and expolisive power in soccer players. Eropean Journal of experimental Biology. 4 (1): 383:386.

Thomas, K., French, D., Hayes, P.R. (2009). The effect of two plyometric training techniques on muscular power and agility in youth soccer players. Journal of Strength and Conditioning Research. 23 (1) 332-335.

Yüksek, S. ve Cicioğlu. İ. (2004). Türk ve Rus judo ümit milli bayan takımlarının bazı fiziksel ve fizyolojik parametrelerinin karşılaştırılması, Spormetre Beden Eğitimi ve Spor Bilimleri Dergisi. 2 (4), ss. 139-140. 